\title{
Novel Mechanisms of Herbal Therapies for Inhibiting HMGB 1 Secretion or Action
}

\author{
Andrew H. Wu, ${ }^{1,2}$ Li He, ${ }^{3}$ Wei Long, ${ }^{2,4}$ Qiuping Zhou, ${ }^{1}$ Shu Zhu, \\ Ping Wang, ${ }^{2}$ Saijun Fan, ${ }^{4}$ and Haichao Wang ${ }^{1,2}$ \\ ${ }^{1}$ Department of Emergency Medicine, North Shore University Hospital, Manhasset, NY 11030, USA \\ ${ }^{2}$ The Feinstein Institute for Medical Research, North Shore-LIJ Health System, 350 Community Drive, Manhasset, NY 11030, USA \\ ${ }^{3}$ Department of Ophthalmology, University of Alabama at Birmingham, Birmingham, AL 35294, USA \\ ${ }^{4}$ The Radiation Medicine Institute of Chinese Academy, Medical Sciences and Peking Union Medical College, Tianjin 300192, China
}

Correspondence should be addressed to Haichao Wang; hwang@nshs.edu

Received 5 August 2014; Revised 24 September 2014; Accepted 1 October 2014

Academic Editor: Mohamed Eddouks

Copyright (c) 2015 Andrew H. Wu et al. This is an open access article distributed under the Creative Commons Attribution License, which permits unrestricted use, distribution, and reproduction in any medium, provided the original work is properly cited.

\begin{abstract}
High mobility group box 1 (HMGB1) is an evolutionarily conserved protein and is constitutively expressed in virtually all types of cells. In response to microbial infections, HMGB1 is secreted from activated immune cells to orchestrate rigorous inflammatory responses. Here we review the distinct mechanisms by which several herbal components inhibit HMGB1 action or secretion, such as by modulating inflammasome activation, autophagic degradation, or endocytic uptake. In light of the reciprocal interactions between these cellular processes, it is possible to develop more effective combinational herbal therapies for the clinical management of inflammatory diseases.
\end{abstract}

\section{Introduction}

High mobility group box 1 (HMGB1), an evolutionarily conserved $30 \mathrm{kDa}$ DNA-binding protein, is ubiquitously expressed in virtually all types of cells. Bearing two nuclearlocalization sequences (NLS), HMGB1 is transported into the nucleus by the nuclear import complexes, thereby maintaining a large nuclear "pool" of preformed protein [1]. It carries two internal repeats of positively charged domains ("HMG boxes" known as "A box" and "B box") in the N-terminus and a continuous stretch of negatively charged (aspartic and glutamic acid) residues in the C-terminus. These HMG boxes enable HMGB1 to bind chromosomal DNA and fulfill its nuclear functions in stabilizing nucleosomal structure and regulating gene expression [1]. The disruption of local expression of HMGB1 renders animals susceptible to infectious [2] or injurious insults $[3,4]$, reinforcing a beneficial role of intracellular HMGB1 in immunity against infection and injury [5] .

In response to infections and injuries, however, HMGB1 is secreted from activated immune cells or passively released from injured cells. Excessive HMGB1 secretion/release adversely contributes to the pathogenesis of infectionand injury-elicited inflammatory diseases. For instance, in animal models of endotoxemia or sepsis (induced by cecal ligation and puncture, CLP), HMGB1-neutralizing antibodies improve survival [6] and rescue rodents from lethal sepsis even if given at $24 \mathrm{~h}$ after CLP $[7,8]$. Similarly, HMGB1-specific antibodies are protective against ischemia/reperfusion [9-11], trauma [12, 13], chemical toxemia [14-16], atherosclerosis [17], gastric ulcer [18], and hyperoxia [19], supporting the pathogenic role of HMGB1 in injury-elicited inflammatory diseases. Furthermore, in animal models of rheumatoid arthritis, anti-HMGB1 agents confer significant protection against joint tissue edema [2022], supporting a pathogenic role for HMGB1 in autoimmune diseases. The establishment of HMGB1 as a mediator of various inflammatory diseases has prompted the search for inhibitors that can attenuate HMGB1 secretion or action. In this review, we summarize the divergent mechanisms by which several herbal therapies effectively inhibit active HMGB1 secretion and action and hope to stimulate interests 
in developing novel HMGB1-targeting therapeutic strategies for the treatment of inflammatory diseases.

\section{Regulation of HMGB1 Secretion}

In response to microbial products (e.g., ds-RNA, CpG-DNA, and endotoxins) $[6,23]$, macrophages/monocytes secrete HMGB1 into the extracellular milieu in a delayed fashion. Lacking a leader peptide sequence, HMGB1 cannot be actively secreted through classical endoplasmic reticulumGolgi exocytotic pathways [6]. Instead, it is first shuttled to cytoplasmic vesicles ("nucleus-to-cytoplasm translocation") and subsequently secreted into the extracellular environment. The nucleus-to-cytoplasm translocation is regulated by posttranslational modifications (e.g., acetylation or phosphorylation) $[24,25]$ of the NLS [5, 26]. For instance, bacterial endotoxin or proinflammatory cytokines (e.g., IFNs) can activate the JAK/STAT1 signaling pathways and acetylate lysine residues within the NLS sites, leading to sequestration of HMGB1 into cytoplasmic vesicles [24, 27-29].

Subsequently, cytoplasmic HMGB1 is secreted into the extracellular space partly through caspase-1-mediated pyroptosis, a proinflammatory programmed cell death by which activated macrophages rapidly release large amounts of cellular contents (including HMGB1 and cytokines such as IL$1 \beta$ ) extracellularly. Indeed, pharmacological inhibition (with a broad-spectrum caspase inhibitor Z-VAD-FMK) or genetic disruption of caspase 1 uniformly reduces HMGB1 secretion $[8,30]$. Specifically, the procaspase- 1 forms a heteromeric protein complex with an adaptor protein (termed apoptosisassociated speck-like protein containing a CARD, ASC), a NOD-like receptor (NLR, e.g., NLRP1, NLRP3, and NLRC4), or a member of the PYHIN family. The resultant protein complex, termed the "inflammasome," is responsible for cleaving procaspase-1 to generate caspase-1, which triggers inflammasome activation as well as pyroptosis [30]. Inflammasome activation occupies an essential role in the regulation of HMGB1 secretion [30, 31], because genetic disruption of key inflammasome components (e.g., caspase 1 or Nalp3) completely blocks LPS/ATP-induced HMGB1 secretion. Recently, the double-stranded RNA-activated protein kinase R (PKR) has been established as a key regulator of inflammasome activation and HMGB1 secretion [31]. Consistently, genetic disruption of PKR expression or pharmacological inhibition of PKR phosphorylation (with 2-aminopurine (2-AP) or 7desacetoxy-6,7-dehydrogedunin (7DG)) markedly reduces inflammasome activation [31, 32], pyroptosis [31, 32], and HMGB1 secretion [31]. Thus, the LPS- or IFN-induced HMGB1 secretion is controlled not only by JAK/STATmediated acetylation and nuclear-cytoplasmic translocation, but also through PKR-mediated inflammasome activation and pyroptosis $[5,26]$.

\section{Extracellular Role of HMGB1 as an Alarmin}

Once released, extracellular HMGB1 functions as an alarmin signal to alert, recruit, and activate immune cells. For instance, HMGB1 binds to various microbial products (e.g., CpG-DNA or LPS), thereby facilitating their recognition by

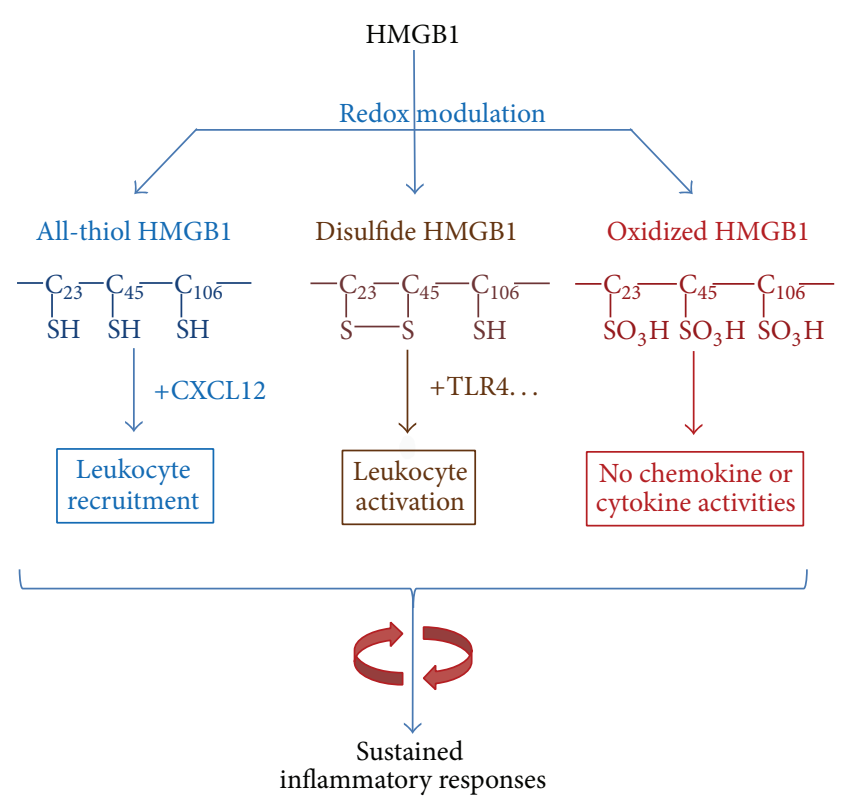

FIGURE 1: Extracellular HMGB1 as a proinflammatory cytokine/ chemokine. The immunological activities of HMGB1 are modulated by the redox status in a divergent fashion, thereby facilitating leukocyte recruitment or activation, resulting in sustained inflammatory responses.

respective receptors to augment inflammatory responses [33]. Harboring three cysteine residues (C23, C45, and C106) that are redox-sensitive, HMGB1 can be modified into three isoforms termed "HMGB1" (all-thiol form), "disulfide HMGB1" (partially oxidized), and oxidized HMGB1 (Figure 1) [34, 35]. The "all-thiol" HMGB1 binds to other chemokines (e.g., CXCL12) and stimulates leukocyte recruitment via the CXCR4 receptor [36]. The "disulfide" HMGB1 can activate immune cells to produce cytokines/chemokines via TLR4 or other receptors such as RAGE [33], TLR2, TLR4 [37-39], TLR9 [23, 33], cluster of differentiation 24 (CD24)/Siglec10 [40], Mac-1 [41], thrombomodulin [42], or single transmembrane domain proteins (e.g., syndecans) [43]. Once fully oxidized, the HMGB1 is devoid of either chemokine or cytokine activities (Figure 1) [34, 35]. Thus, HMGB1 can function either as a chemokine to stimulate leukocyte migration $[41,44,45]$ or as a cytokine to activate macrophages $[37,46,47]$ and endothelial cells $[48,49]$ to produce more cytokines, chemokines, and adhesion molecules.

\section{Distinct Mechanisms of Herbal Inhibition of HMGB 1 Secretion or Action}

Recently, a number of herbal extracts (e.g., Danggui, Mung bean, and Prunella vulgaris) [50-52] and components (e.g., nicotine, EGCG, tanshinone, glycyrrhizin, chlorogenic acid, emodin-6-O- $\beta$-D-glucoside, rosmarinic acid, isorhamnetin3-O-galactoside, persicarin, forsythoside B, chloroquine, acteroside, and shikonin) (Figure 2) [53-65] have been shown effective in inhibiting endotoxin-induced HMGB1 secretion. Here we compare the distinct mechanisms by which several 
<smiles>O=C(C=Cc1ccc(O)c(O)c1)OC1CC(O)(C(=O)O)CC(O)[C@@H]1O</smiles>

Chlorogenic acid<smiles>O=C(C=Cc1ccc(O)c(O)c1)OC(Cc1ccc(O)c(O)c1)C(=O)O</smiles>

Rosmarinic acid

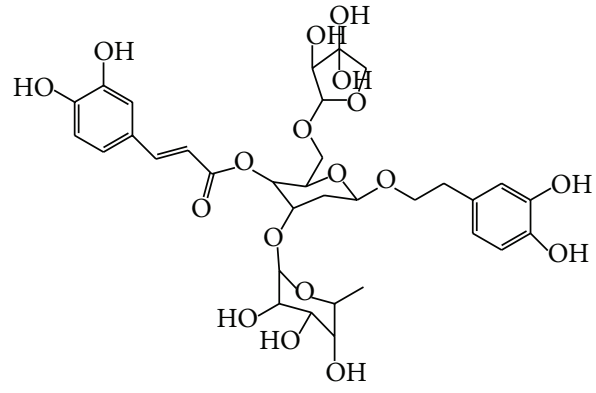

Forsythoside B<smiles>CC(=O)OC(C)(C)C(C)(C)C</smiles><smiles>O=C(OC1Cc2c(O)cc(O)cc2OC1c1cc(O)c(O)c(O)c1)c1cc(O)c(O)c(O)c1</smiles><smiles>O=c1c(O)c(-c2ccc(O)c(O)c2)oc2cc(O)cc(O)c12</smiles><smiles>COc1cc(C2=C(OS(=O)(=O)O)C(O)c3c(O)cc(O)cc3O2)ccc1O</smiles>

Epigallocatechin-3-gallate (EGCG)

Quercetin

Persicarin<smiles>Cc1cc(O)c2c(c1)C(=O)c1cc(OC(O)C3C(O)C(O)C(O)C(O)C3O)cc(O)c1C2=O</smiles><smiles>Cc1c(S(N)(=O)=O)oc2c1C(=O)C(=O)c1c-2ccc2c1CCCC2(C)C</smiles>

$\mathrm{HO}^{-}$

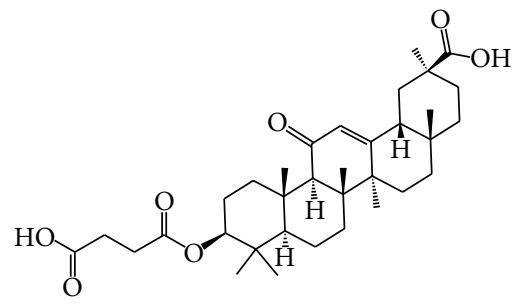

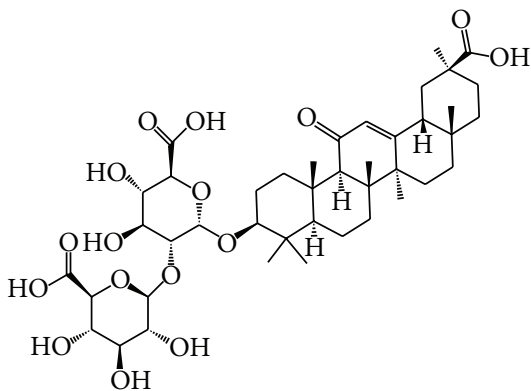

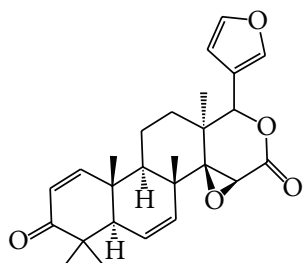

Carbenoxolone (CBX) Glycyrrhizin (glycyrrhizic acid) (GZA)

7-Desacetoxy-6,7-dehydrogedunin (7-DG)

FIGURE 2: Chemical structures of HMGB1-inhibiting herbal components.

herbal components effectively inhibit HMGB1 action or secretion.

4.1. Glycyrrhizin (GZA) Binds to HMGB1 to Inhibit Its Secretion or Action. Gancao (radix glycyrrhizae, meaning "sweet root" in Greek or "licorice" in English) has been traditionally used in the clinical management of various inflammatory diseases including peptic ulcer, hepatitis, and pulmonary bronchitis for many centuries. Its anti-inflammatory properties are attributable to a major component, glycyrrhizin (GZA, Figure 2), which has been proven beneficial in animal models of hepatitis [66], hepatic ischemia/reperfusion (I/R) injury $[67,68]$, endotoxin- and acetaminophen-induced liver injury [69, 70], influenza [71], lung inflammation [72], 


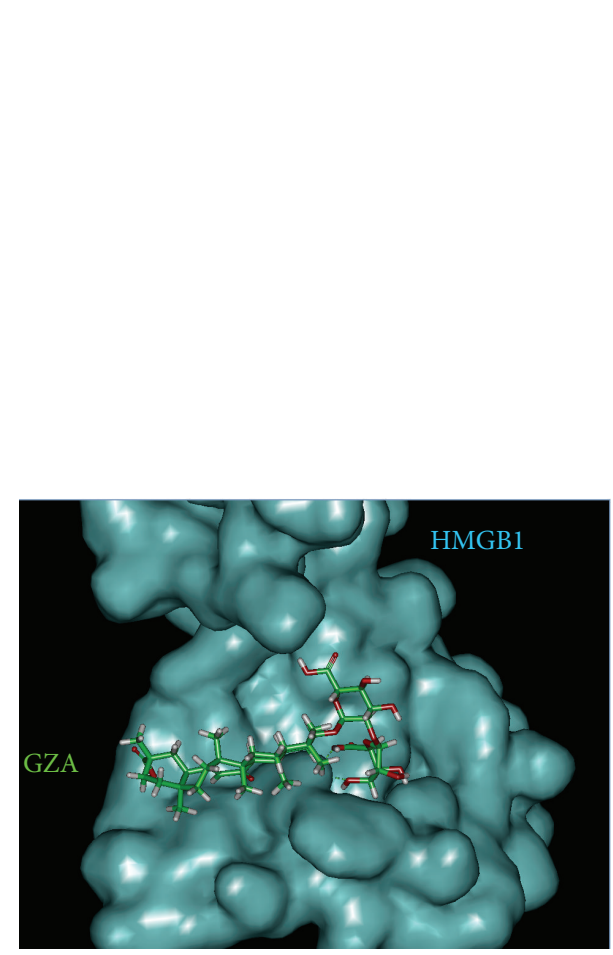

(a)
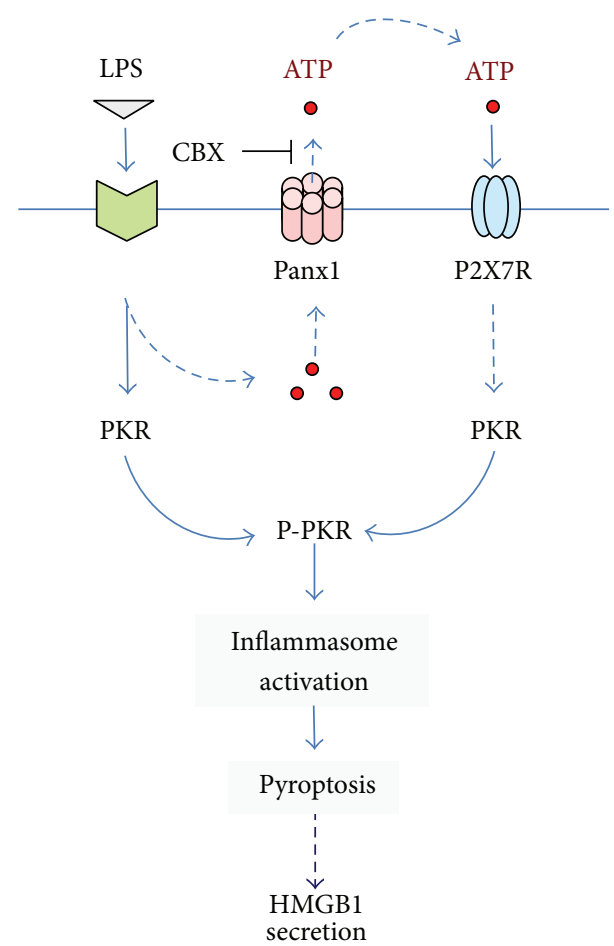

(b)

FIGURE 3: Divergent inhibition of HMGB1 action or secretion. (a) GZA binds to the shallow cave surface of HMGB1 boxes. Computer-assisted molecular docking of HMGB1 with GZA: the blue area represents surface of HMGB1 box A, whereas the chemical structure of GZA is shown in green. (b) CBX inhibits LPS-induced HMGB1 secretion by preventing PKR activation. Prolonged stimulation with crude LPS may lead to panx-1 hemichannel-mediated ATP efflux and upregulation of PKR expression. Extracellular ATP then binds to P2X7R and activates the ATPgated P2X7R and panx-1 hemichannels, leading to PKR phosphorylation and subsequent inflammasome-dependent HMGB1 secretion. CBX may block LPS-induced ATP efflux through panx-1, thereby impairing ATP/P2X7R-mediated PKR activation and subsequent inflammasomedependent HMGB1 secretion.

intracerebral hemorrhage [73], cerebral I/R injury [74, 75], seizure [76], endotoxemia [56,77], and colitis [78]. Sakamoto et al. first employed biochemical techniques and demonstrated that GZA directly interacted with HMGB1 to induce certain conformational changes that prevented DNA-binding [79]. Subsequently, Mollica et al. (2007) used nuclear magnetic resonance (NMR) and fluorescence techniques and confirmed that GZA indeed docked into the DNA-binding concaves of both HMGB1 boxes (Figure 3(a)) [80, 81]. In agreement with these findings, most GZA-mediated protective effects have been associated with the inhibition of HMGB1 release $[56,68,75,76]$ or cytokine/chemokine activities [56, 70, 73, 82].

4.2. Carbenoxolone (CBX) Prevents PKR Activation. The replacement of the glucuronic acid in GZA by succinic acid gives rise to a new compound, carbenoxolone (CBX, Figure 2), a drug previously prescribed for esophageal ulceration and inflammation [83]. Since its inception, CBX has been shown to dose-dependently inhibit a variety of biological activities including the gap junctions $(50-100 \mu \mathrm{M})$ and the panx-1 hemichannels $\left(\mathrm{EC}_{50}=1-4 \mu \mathrm{M}\right)[84,85]$. Recently, we discovered that CBX also effectively inhibited LPS-induced HMGB1 secretion, with an estimated $\mathrm{IC}_{50}$ and $\mathrm{IC}_{100} \sim 5 \mu \mathrm{M}$ and $10 \mu \mathrm{M}$, respectively [86]. However, it is unlikely that
CBX inhibits the LPS-induced HMGB1 secretion through impairing the gap junctions, because macrophages do not form gap junctions, and the concentrations of CBX used to block gap junctions (i.e., $50-100 \mu \mathrm{M}$ ) are much higher than those (i.e., 5-10 $\mu \mathrm{M}$ ) used to abrogate LPS-induced HMGB1 secretion [86].

The involvement of PKR in CBX-mediated inhibition of HMGB1 secretion is supported by several lines of evidence. First, ultrapure LPS (free from contaminating bacterial proteins and nucleic acids) fails to trigger HMGB1 secretion unless the initial LPS $(10 \mu \mathrm{g} / \mathrm{mL})$ priming is accompanied by a second stimulus (e.g., ATP) [30, 31], which promotes PKR phosphorylation [31] and inflammasome activation [8789]. Second, crude LPS (containing trace amounts of bacterial proteins and nucleic acids) triggers marked upregulation of PKR expression (>2-fold) and phosphorylation ( $>8$-fold) and effectively induces HMGB1 secretion [6]. It is possible that the crude LPS may prime macrophages by upregulating PKR expression and simultaneously eliciting panx-1-mediated ATP release (Figure 3(b)). Extracellular ATP then binds and activates the purinergic P2X7 receptor (P2X7R) [90], which further elevates panx-1 hemichannel activity to induce feedforwarding ATP release and subsequent PKR/inflammasome activation and HMGB1 secretion [87-89] (Figure 3(b)). This hypothesis is consistent with the finding that panx-1 
physically interacts with both P2X7R and components of the NLRP3 inflammasome [91, 92]. It is also supported by our observations that both P2X7R antagonists (e.g., oxidized ATP or oATP) and panx-1 inhibitors (e.g., CBX) effectively inhibit LPS-induced dye uptake, PKR activation, and HMGB1 secretion (Figure 3(b)) [31, 93]. Consistently, CBX $(10 \mu \mathrm{M})$ has recently been proven effective in inhibiting the panx1-mediated ATP release in response to hypoxia [94], sheer stress [95], and low oxygen tension [96] and blocking HMGB1 secretion by neurons during cortical spreading depression [97].

4.3. Epigallocatechin-3-Gallate (EGCG) Stimulates Autophagic HMGB1 Degradation. Green tea contains a class of biologically active polyphenols called catechins such as the epigallocatechin-3-gallate (EGCG). At relatively low concentrations $(10-15 \mu \mathrm{M})$, EGCG partially inhibits LPS-induced release of TNF and IL-12 but dramatically attenuates IL- 6 and several chemokines (including MIP-1 $\alpha$, MIP-1 $\beta$, MIP-2, RANTES, KC, MCP-1, and CXCL16) [54]. Similarly, EGCG dose-dependently abrogates LPS-induced HMGB1 secretion, with an estimated $\mathrm{IC}_{50}<1.0 \mu \mathrm{M}$ [54]. Notably, significant inhibition of HMGB1 secretion is still achieved even when EGCG is added 2-6 h after LPS stimulation [54], suggesting EGCG as an effective HMGB1 inhibitor. It now appears that EGCG prevents the LPS-induced HMGB1 secretion strategically by destroying HMGB1 in the cytoplasm via a cellular degradation process, autophagy (self-eating) (Figure 4).

As an evolutionarily conserved cellular process for degrading damaged cytoplasmic macromolecules, autophagy begins with the formation of double-membraned structures, which elongate and engulf portions of the cytoplasm to form autophagosomes. Subsequently, autophagosomes fuse with lysosomes to form degradative autophagolysosomes, where the engulfed contents are degraded by acidic lysosomal hydrolases. Indeed, EGCG can be trafficked into autophagosomes within $6 \mathrm{~h}$ and then destined to the lysosomal-associated membrane protein 2- (LAMP2-) containing autophagolysosomes within $16 \mathrm{~h}$ [98]. Meanwhile, EGCG conjugates to cytoplasmic HMGB1, leading to the formation of EGCG-HMGB1 complexes (dimmer, trimmer, tetramer, and oligomer) (Figure 4) [98]. This is consistent with previous findings that EGCG may conjugate to proteins either covalently with the free thiol group of cysteine residues [99] or noncovalently via hydrogen bonding, aromatic stacking, or hydrophobic interactions [100]. Because these large EGCG-HMGB1 complexes cannot physically pass through the narrow pore of the proteasome barrel of the ubiquitinproteasome pathway, they trigger the autophagic degradation process. Consistently, at the concentrations effective for inhibiting HMGB1 secretion, EGCG dramatically enhances the formation of autophagosomes [98]. In contrast, the coaddition of autophagy inhibitors (e.g., 3-methyladenine) impairs EGCG-mediated inhibition of HMGB1 secretion, thereby leading to a dramatic accumulation of HMGB1 aggregates in macrophages. Recently, EGCG has also been proven effective in stimulating autophagy in other cell types including breast cancer cells [98], hepatocytes [101], retinal pigment epithelial cells [102], and vascular endothelial

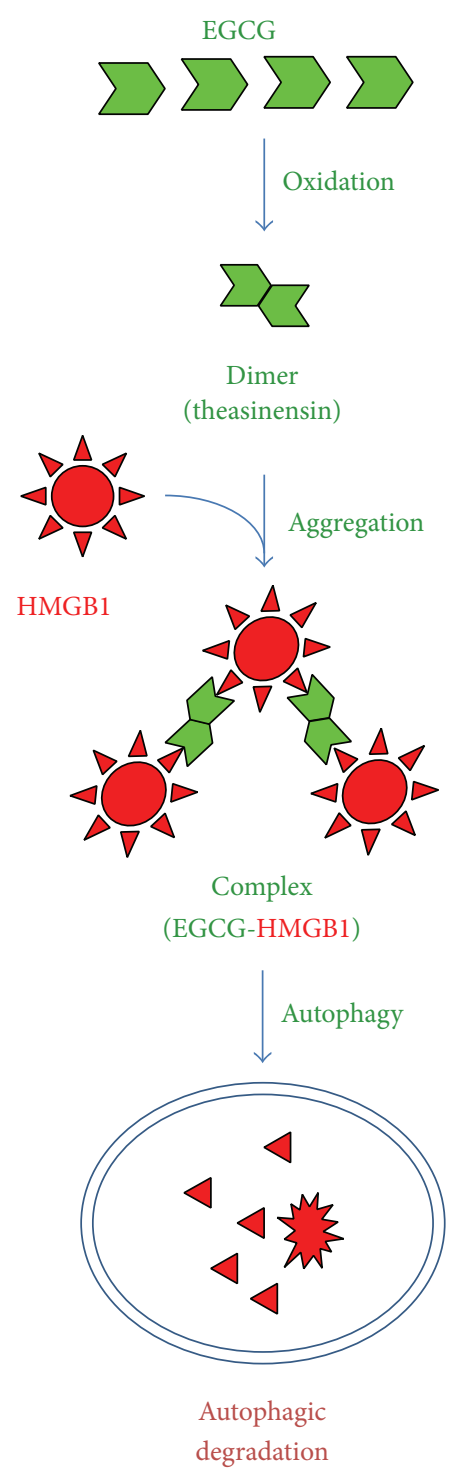

FIgURE 4: EGCG induces autophagic HMGB1 degradation. Green tea EGCG induces HMGB1 aggregation, thereby triggering autophagic HMGB1 degradation in macrophage cultures.

cells [103]. Given the possibility that HMGB1 interacts with autophagy regulators (e.g., beclin-1) in the cytoplasm [104, 105], it will be important to investigate whether HMGB1 occupies a critical role in EGCG-mediated autophagy. This is relevant because recent studies indicate that bacterial endotoxin induces significantly less autophagy in HMGB1deficient macrophages [2].

4.4. Tanshinone IIA Sodium Sulfonate (TSN-SS) Stimulates Endocytic HMGB1 Uptake. Danshen is a medicinal herb that contains several red pigments including tanshinones I, II, and IV and cryptotanshinone, which exhibit various anti-inflammatory properties. Accounting for $5-6 \%$ of the total dry weight of Danshen root, tanshinone IIA dosedependently attenuates LPS-induced HMGB1 secretion, with 
an estimated $\mathrm{IC}_{50}<25 \mu \mathrm{M}$. However, its poor water solubility may adversely affect the bioavailability and therapeutic efficacy of tanshinone IIA [55], thereby prompting the exploration of water-soluble derivatives as more effective HMGB1 inhibitors. One such compound, tanshinone IIA sodium sulfonate (TSN-SS), dose-dependently inhibits LPSinduced HMGB1 secretion with an estimated $\mathrm{IC}_{50}<10 \mu \mathrm{M}$. At the doses that completely prevent HMGB1 secretion, TSNSS does not affect endotoxin-induced release of most other cytokines and chemokines (such as IL-6, IL-12p40/p70, KC, MCP-1, MIP-1 $\alpha$, MIP-2, and TNF), indicating a selectivity for TSN-SS in inhibiting HMGB1 secretion.

Unlike EGCG, TSN-SS itself is unable to stimulate autophagic HMGB1 degradation [55] but instead induces the internalization of exogenous HMGB1 into cytoplasmic vesicles possibly through clathrin- and caveolin-dependent endocytosis (Figure 5) [106]. Indeed, specific inhibitors for both clathrin- (e.g., chlorpromazine) and caveolindependent (e.g., nystatin and indomethacin) endocytosis uniformly attenuate the TSN-SS-mediated HMGB1 uptake. Surprisingly, the depletion of several HMGB1 receptors (e.g., TLR2, TLR4, or RAGE) does not impair TSN-SSmediated enhancement of HMGB1 uptake, suggesting that other HMGB1-binding cell surface proteins (such as Mac-1, thrombomodulin, or syndecan) may be required for the TSNSS-mediated HMGB1 uptake.

Given the regulatory role of HMGB1 in autophagy [2, 104, 105], the TSN-SS-mediated HMGB1 endocytosis may be linked to autophagy (Figure 5). When occurring simultaneously, endocytosis and autophagy can converge on a common lysosome-dependent pathway, leading to eventual HMGB1 degradation. Specifically, endosomes fuse with autophagosomes to form amphisomes [107, 108], which then merge with lysosomes to form autolysosomes, where the amphisome contents are digested by lysosomal enzymes [109]. In the presence of TSN-SS, exogenous HMGB1 was detected in increased number of larger cytoplasmic vesicles that colocalized with autophagy-(LC3-positive) punctate structures, suggesting that HMGB1-containing endosomes may have been fused with autophagosomes to form amphisomes. The internalized HMGB1 is then possibly degraded via the lysosome-dependent pathway, because bafilomycin A1, a specific inhibitor of autophagosome-lysosome fusion, prevents the degradation of LC3-II and exogenous HMGB1. Taken together, these results suggest that TSN-SS facilitates endocytosis of exogenous HMGB1, leading to subsequent HMGB1 degradation via a lysosome-dependent pathway (Figure 5). Notably, even when given several hours after the endotoxin stimulation, TSN-SS still effectively blocks HMGB1 secretion. It is thus possible to strategically administer TSN-SS in a delayed fashion to pharmacologically "recycle" injurious proinflammatory mediators (such as HMGB1) back to innate immune cells. TSN-SS has already been used in China as a medicine for patients with cardiovascular disorders, and its capacity to facilitate endocytic HMGB1 uptake by professional phagocytes may provide basis for the treatment of both infection- and injury-elicited inflammatory diseases [26].

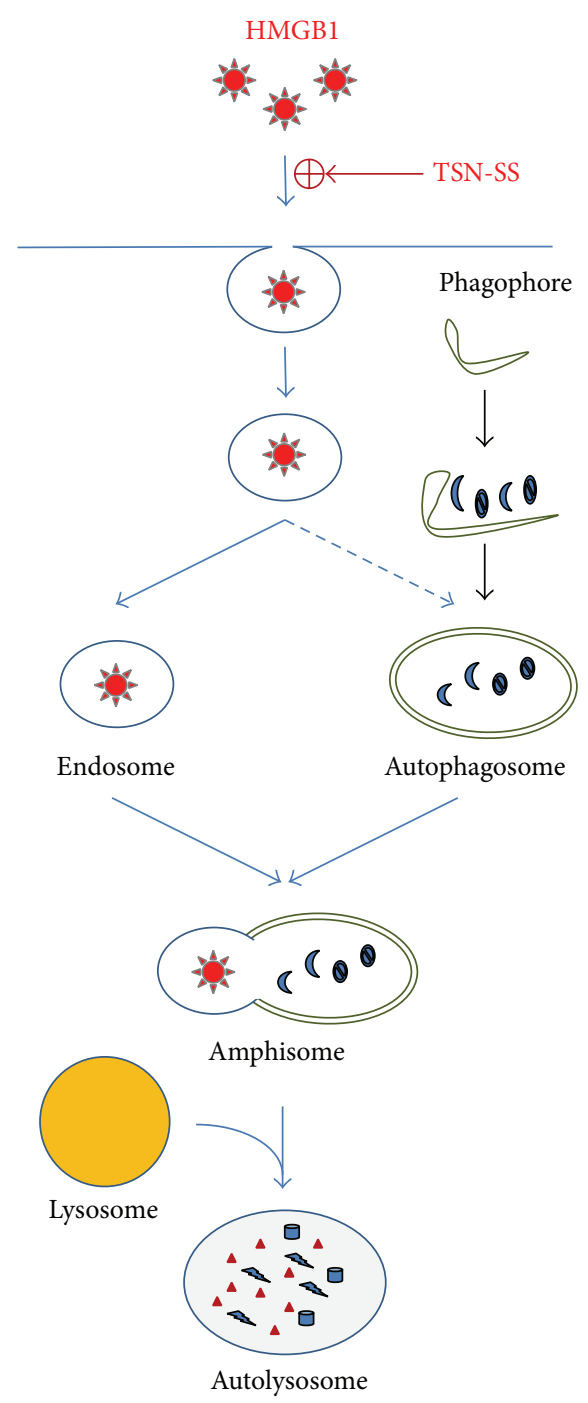

FIgURE 5: TSN-SS stimulates endocytic HMGB1 uptake. TSNSS facilitated internalization of exogenous HMGB1 possibly via clathrin- and caveolin-dependent endocytosis into cytoplasmic vesicles that eventually mature into endosomes. Consequently, it likely triggers another cellular degradation process, autophagy, during which cytoplasmic macromolecules are engulfed by doublemembraned cytoplasmic vesicles termed autophagosomes. Subsequently, these HMGB1-containing endosomes could be fused with other cytoplasmic vesicles (such as autophagosomes) to form amphisomes, where the internalized HMGB1 was likely degraded via a lysosome-dependent mechanism.

\section{Therapeutic Efficacy of HMGB 1-Inhibiting Herbal Components}

Given the capacity of various herbal components in preventing endotoxin-induced HMGB1 secretion, we explored their efficacy in animal models of CLP-induced sepsis. Considering the late and prolonged kinetics of HMGB1 accumulation in experimental sepsis [7], the first dose of HMGB1 inhibitors was given in a delayed fashion, $24 \mathrm{~h}$ after the onset of sepsis. Repetitive intraperitoneal administration 
of EGCG [54], TSN-SS [55], or CBX [86], at 24, 48, and $72 \mathrm{~h}$ after CLP, significantly increased animal survival rates. When given orally, EGCG still rescued mice from lethal sepsis, significantly increasing animal survival rates from $16 \%$ to $44 \%$ [98]. Intriguingly, we found that EGCG facilitated bacterial elimination in selective organs (e.g., the liver and lung) in an animal model of sepsis [110]. Importantly, these herbal components have also been proven beneficial in other models of inflammation such as ischemia [68, 111-117], trauma [118-120], crush injury [121], radiation [122, 123], and chemical toxemia $[124,125]$. It is not yet known whether these protective effects are also associated with inhibition of HMGB1 release or chemokine/cytokine activities.

Recently, a herbal remedy consisting of five herbs (Danggui, Danshen, Honghua, Chuanxiong, and Chishao) has been developed in China for treating septic patients. This combinational therapy, termed "Xuebijing," has been proven to be protective experimentally in animal model of sepsis [126] or clinically in patients with sepsis $[127,128]$. In light of the distinct but occasionally complementary mechanisms of herbal inhibition of HMGB1 release or action, combinational therapy with multiple herbs might result in an improved therapeutic efficacy. For instance, the induction of autophagy by EGCG may provide a negative feedback regulation of inflammasome activation at multiple levels such as by eliminating damaged mitochondria (to prevent mitochondrial DNA release) [129], removing active inflammasomes [129, 130], and destroying cytoplasmic HMGB1 [98]. It is thus important to test whether a better protection could be achieved by combinational therapy with several HMGB1 inhibitors that divergently modulate autophagy (e.g., EGCG) and inflammasome (e.g., CBX). These important studies may pave the road for future clinical studies to explore the therapeutic potential of additional herbal cocktail for the treatment of sepsis and other inflammatory diseases.

\section{Conclusions}

HMGB1 is secreted by activated macrophages/monocytes through complex mechanisms including PKR-dependent inflammasome activation and pyroptosis. A growing number of herbal components have been proven to be effective in inhibiting endotoxin-induced HMGB1 secretion through divergently distinct mechanisms such as preventing PKR/inflammasome activation, stimulating HMGB1 autophagic degradation, and enhancing endocytic HMGB1 uptake. In light of the intricate relationship between endocytosis, autophagy, and inflammasome activation, it is important to test whether a better protection could be achieved by combinational therapy with several anti-HMGB1 agents.

\section{Conflict of Interests}

The authors declare that there is no conflict of interests regarding the publication of this paper.

\section{Authors' Contribution}

Andrew $\mathrm{H}$. Wu and $\mathrm{Li} \mathrm{He}$ equally contributed to this paper.

\section{Acknowledgments}

The authors are grateful to Echo Wang for her critical and constructive comments. Work in authors' laboratory was supported by grants from the National Center of Complementary and Alternative Medicine (NCCAM, R01AT005076) and the National Institute of General Medical Sciences (NIGMS, R01GM063075).

\section{References}

[1] R. Kang, R. Chen, and Q. Zhang, "HMGB1 in health and disease," Molecular Aspects of Medicine, 2014.

[2] H. Yanai, A. Matsuda, J. An et al., "Conditional ablation of HMGB1 in mice reveals its protective function against endotoxemia and bacterial infection," Proceedings of the National Academy of Sciences of the United States of America, vol. 110, no. 51, pp. 20699-20704, 2013.

[3] H. Huang, G. W. Nace, K.-A. Mcdonald et al., "Hepatocytespecific high-mobility group box 1 deletion worsens the injury in liver ischemia/reperfusion: a role for intracellular highmobility group box 1 in cellular protection," Hepatology, vol. 59, no. 5, pp. 1984-1997, 2014.

[4] R. Kang, Q. Zhang, W. Hou et al., "Intracellular HMGB1 inhibits inflammatory nucleosome release and limits acute pancreatitis in mice," Gastroenterology, vol. 146, no. 4, pp. 1097-1107, 2014.

[5] B. Lu, C. Wang, M. Wang et al., "Molecular mechanism and therapeutic modulation of high mobility group box 1 release and action: an updated review," Expert Review of Clinical Immunology, vol. 10, no. 6, pp. 713-727, 2014.

[6] H. Wang, O. Bloom, M. Zhang et al., "HMG-1 as a late mediator of endotoxin lethality in mice," Science, vol. 285, no. 5425, pp. 248-251, 1999.

[7] H. Yang, M. Ochani, J. Li et al., "Reversing established sepsis with antagonists of endogenous high-mobility group box 1," Proceedings of the National Academy of Sciences of the United States of America, vol. 101, no. 1, pp. 296-301, 2004.

[8] S. Qin, H. Wang, R. Yuan et al., "Role of HMGB1 in apoptosismediated sepsis lethality," The Journal of Experimental Medicine, vol. 203, no. 7, pp. 1637-1642, 2006.

[9] H. Wu, J. Ma, P. Wang et al., "HMGB1 contributes to kidney ischemia reperfusion injury," Journal of the American Society of Nephrology, vol. 21, no. 11, pp. 1878-1890, 2010.

[10] A. Tsung, R. Sahai, H. Tanaka et al., "The nuclear factor HMGB1 mediates hepatic injury after murine liver ischemiareperfusion," Journal of Experimental Medicine, vol. 201, no. 7, pp. 1135-1143, 2005.

[11] J. Qiu, M. Nishimura, Y. Wang et al., "Early release of HMGB1 from neurons after the onset of brain ischemia," Journal of Cerebral Blood Flow and Metabolism, vol. 28, no. 5, pp. 927-938, 2008.

[12] Y. Okuma, K. Liu, H. Wake et al., "Anti-high mobility group box-1 antibody therapy for traumatic brain injury," Annals of Neurology, vol. 72, no. 3, pp. 373-384, 2012.

[13] J. Shimazaki, N. Matsumoto, H. Ogura et al., "Systemic involvement of high-mobility group box 1 protein and therapeutic effect of anti-high-mobility group box 1 protein antibody in a rat model of crush injury," Shock, vol. 37, no. 6, pp. 634-638, 2012. 
[14] R. Yang, S. Zhang, A. Cotoia, N. Oksala, S. Zhu, and J. Tenhunen, "High mobility group B1 impairs hepatocyte regeneration in acetaminophen hepatotoxicity," BMC Gastroenterology, vol. 12, article 45, 2012.

[15] Y. Nadatani, T. Watanabe, T. Tanigawa et al., "High mobility group box 1 promotes small intestinal damage induced by nonsteroidal anti-inflammatory drugs through toll-like receptor 4," American Journal of Pathology, vol. 181, no. 1, pp. 98-110, 2012.

[16] R.-R. Zhou, H.-B. Liu, J.-P. Peng et al., "High mobility group box chromosomal protein 1 in acute-on-chronic liver failure patients and mice with ConA-induced acute liver injury," Experimental and Molecular Pathology, vol. 93, no. 2, pp. 213219, 2012.

[17] Y. Hirata, H. Kurobe, M. Higashida et al., "HMGB1 plays a critical role in vascular inflammation and lesion formation via toll-like receptor 9," Atherosclerosis, vol. 231, no. 2, pp. 227-233, 2013.

[18] Y. Nadatani, T. Watanabe, T. Tanigawa et al., "High-mobility group box 1 inhibits gastric ulcer healing through toll-like receptor 4 and receptor for advanced glycation end products," PLoS ONE, vol. 8, no. 11, Article ID e80130, 2013.

[19] V. S. Patel, R. A. Sitapara, A. Gore et al., "High mobility group box-1 mediates hyperoxia-induced impairment of Pseudomonas aeruginosa clearance and inflammatory lung injury in mice," American Journal of Respiratory Cell and Molecular Biology, vol. 48 , no. 3, pp. 280-287, 2013.

[20] R. Kokkola, J. Li, E. Sundberg et al., "Successful treatment of collagen-induced arthritis in mice and rats by targeting extracellular high mobility group box chromosomal protein 1 activity," Arthritis and Rheumatism, vol. 48, no. 7, pp. 2052-2058, 2003.

[21] H. Schierbeck, P. Lundbäck, K. Palmblad et al., "Monoclonal anti-HMGB1 (high mobility group box chromosomal protein 1) antibody protection in two experimental arthritis models," Molecular Medicine, vol. 17, no. 9-10, pp. 1039-1044, 2011.

[22] T. Östberg, K. Kawane, S. Nagata et al., "Protective targeting of high mobility group box chromosomal protein 1 in a spontaneous arthritis model," Arthritis and Rheumatism, vol. 62, no. 10, pp. 2963-2972, 2010.

[23] S. Ivanov, A.-M. Dragoi, X. Wang et al., "Anovel role for HMGB1 in TLR9-mediated inflammatory responses to CpGDNA," Blood, vol. 110, no. 6, pp. 1970-1981, 2007.

[24] B. Lu, D. J. Antoine, K. Kwan et al., "JAK/STAT1 signaling promotes HMGB1 hyperacetylation and nuclear translocation," Proceedings of the National Academy of Sciences of the United States of America, vol. 111, no. 8, pp. 3068-3073, 2014.

[25] J. H. Youn and J.-S. Shin, "Nucleocytoplasmic shuttling of HMGB1 is regulated by phosphorylation that redirects it toward secretion," The Journal of Immunology, vol. 177, no. 11, pp. 78897897, 2006.

[26] H. Wang, M. F. Ward, and A. E. Sama, "Targeting HMGB1 in the treatment of sepsis," Expert Opinion on Therapeutic Targets, vol. 18, no. 3, pp. 257-268, 2014.

[27] B. Rendon-Mitchell, M. Ochani, J. Li et al., "IFN- $\gamma$ induces high mobility group box 1 protein release partly through a TNFdependent mechanism," The Journal of Immunology, vol. 170, no. 7, pp. 3890-3897, 2003.

[28] S. Gardella, C. Andrei, D. Ferrera et al., "The nuclear protein HMGB1 is secreted by monocytes via a non-classical, vesiclemediated secretory pathway," EMBO Reports, vol. 3, no. 10, pp. 995-1001, 2002.
[29] T. Bonaldi, F. Talamo, P. Scaffidi et al., "Monocytic cells hyperacetylate chromatin protein HMGB1 to redirect it towards secretion," The EMBO Journal, vol. 22, no. 20, pp. 5551-5560, 2003.

[30] M. Lamkanfi, A. Sarkar, L. Vande Walle et al., "Inflammasomedependent release of the alarmin HMGB1 in endotoxemia," Journal of Immunology, vol. 185, no. 7, pp. 4385-4392, 2010.

[31] B. Lu, T. Nakamura, K. Inouye et al., "Novel role of PKR in inflammasome activation and HMGB1 release," Nature, vol. 488, no. 7413, pp. 670-674, 2012.

[32] E. C. Hett, L. H. Slater, K. G. Mark et al., "Chemical genetics reveals a kinase-independent role for protein kinase $\mathrm{R}$ in pyroptosis," Nature Chemical Biology, vol. 9, no. 6, pp. 398-405, 2013.

[33] J. Tian, A. M. Avalos, S.-Y. Mao et al., “Toll-like receptor 9dependent activation by DNA-containing immune complexes is mediated by HMGB1 and RAGE," Nature Immunology, vol. 8, no. 5, pp. 487-496, 2007.

[34] E. Venereau, M. Casalgrandi, M. Schiraldi et al., "Mutually exclusive redox forms of HMGB1 promote cell recruitment or proinflammatory cytokine release," Journal of Experimental Medicine, vol. 209, no. 9, pp. 1519-1528, 2012.

[35] H. Yang, P. Lundbäck, L. Ottosson et al., "Redox modification of cysteine residues regulates the cytokine activity of high mobility group box-1 (HMGB1)," Molecular Medicine, vol. 18, no. 2, pp. 250-259, 2012.

[36] M. Schiraldi, A. Raucci, L. M. Munoz et al., "HMGB1 promotes recruitment of inflammatory cells to damaged tissues by forming a complex with CXCL12 and signaling via CXCR4," Journal of Experimental Medicine, vol. 209, no. 3, pp. 551-563, 2012.

[37] M. Yu, H. Wang, A. Ding et al., "HMGB1 signals through tolllike receptor (TLR) 4 and TLR2," Shock, vol. 26, no. 2, pp. 174$179,2006$.

[38] T. Ha, Y.Xia, X. Liu et al., "Glucan phosphate attenuates myocardial HMGB1 translocation in severe sepsis through inhibiting NF- $\kappa$ B activation," The American Journal of Physiology-Heart and Circulatory Physiology, vol. 301, no. 3, pp. H848-H855, 2011.

[39] M. Xiang, X. Shi, Y. Li et al., "Hemorrhagic shock activation of NLRP3 inflammasome in lung endothelial cells," The Journal of Immunology, vol. 187, no. 9, pp. 4809-4817, 2011.

[40] G.-Y. Chen, J. Tang, P. Zheng, and Y. Liu, "CD24 and siglec-10 selectively repress tissue damage_-induced immune responses," Science, vol. 323, no. 5922, pp. 1722-1725, 2009.

[41] V. V. Orlova, E. Y. Choi, C. Xie et al., "A novel pathway of HMGB1-mediated inflammatory cell recruitment that requires Mac-1-integrin," The EMBO Journal, vol. 26, no. 4, pp. 1129-1139, 2007.

[42] K. Abeyama, D. M. Stern, Y. Ito et al., "The N-terminal domain of thrombomodulin sequesters high-mobility groupB1 protein, a novel antiinflammatory mechanism," Journal of Clinical Investigation, vol. 115, no. 5, pp. 1267-1274, 2005.

[43] M. Salmivirta, H. Rauvala, K. Elenius, and M. Jalkanen, "Neurite growth-promoting protein (amphoterin, p30) binds syndecan," Experimental Cell Research, vol. 200, no. 2, pp. 444451, 1992.

[44] D. Yang, Q. Chen, H. Yang, K. J. Tracey, M. Bustin, and J. J. Oppenheim, "High mobility group box-1 protein induces the migration and activation of human dendritic cells and acts as an alarmin," Journal of Leukocyte Biology, vol. 81, no. 1, pp. 5966, 2007. 
[45] I. E. Dumitriu, M. E. Bianchi, M. Bacci, A. A. Manfredi, and P. Rovere-Querini, "The secretion of HMGB1 is required for the migration of maturing dendritic cells," Journal of Leukocyte Biology, vol. 81, no. 1, pp. 84-91, 2007.

[46] R. Kokkola, Å. Andersson, G. Mullins et al., "RAGE is the major receptor for the proinflammatory activity of HMGB1 in rodent macrophages," Scandinavian Journal of Immunology, vol. 61, no. 1, pp. 1-9, 2005.

[47] M. Pedrazzi, M. Patrone, M. Passalacqua et al., "Selective proinflammatory activation of astrocytes by high-mobility group box 1 protein signaling," The Journal of Immunology, vol. 179, no. 12, pp. 8525-8532, 2007.

[48] C. Fiuza, M. Bustin, S. Talwar et al., "Inflammation-promoting activity of HMGB1 on human microvascular endothelial cells," Blood, vol. 101, no. 7, pp. 2652-2660, 2003.

[49] C. J. Treutiger, G. E. Mullins, A. S. Johansson et al., "High mobility group 1 B-box mediates activation of human endothelium," Journal of Internal Medicine, vol. 254, no. 4, pp. 375-385, 2003.

[50] H. Wang, W. Li, J. Li et al., "The aqueous extract of a popular herbal nutrient supplement, Angelica sinensis, protects mice against lethal endotoxemia and sepsis," Journal of Nutrition, vol. 136, no. 2, pp. 360-365, 2006.

[51] S. Zhu, W. Li, J. Li, A. Jundoria, A. E. Sama, and H. Wang, "It is not just folklore: the aqueous extract of mung bean coat is protective against sepsis," Evidence-Based Complementary and Alternative Medicine, vol. 2012, Article ID 498467, 10 pages, 2012.

[52] M. S. Jun, H. S. Kim, Y. M. Kim et al., "Ethanol extract of Prunella vulgaris var. lilacina inhibits HMGB1 release by induction of heme oxygenase-1 in LPS-activated RAW 264.7 cells and CLP-induced septic mice," Phytotherapy Research, vol. 26, no. 4, pp. 605-612, 2012.

[53] H. Wang, H. Liao, M. Ochani et al., "Cholinergic agonists inhibit HMGB1 release and improve survival in experimental sepsis," Nature Medicine, vol. 10, no. 11, pp. 1216-1221, 2004.

[54] W. Li, M. Ashok, J. Li, H. Yang, A. E. Sama, and H. Wang, "A major ingredient of green tea rescues mice from lethal sepsis partly by inhibiting HMGB1," PLoS ONE, vol. 2, no. 11, Article ID el153, 2007.

[55] W. Li, J. Li, M. Ashok et al., "A cardiovascular drug rescues mice from lethal sepsis by selectively attenuating a late-acting proinflammatory mediator, high mobility group box 1 ," the Journal of Immunology, vol. 178, no. 6, pp. 3856-3864, 2007.

[56] W. Wang, F. Zhao, Y. Fang et al., "Glycyrrhizin protects against porcine endotoxemia through modulation of systemic inflammatory response," Critical Care, vol. 17, no. 2, article R44, 2013.

[57] C.-H. Lee, S.-J. Yoon, and S.-M. Lee, "Chlorogenic acid attenuates high mobility group box 1 (HMGB1) and enhances host defense mechanisms in murine sepsis," Molecular Medicine, vol. 18, no. 11, pp. 1437-1448, 2012.

[58] W. Lee, S.-K. Ku, T. H. Kim, and J.-S. Bae, "Emodin-6-O- $\beta$-Dglucoside inhibits HMGB1-induced inflammatory responses in vitro and in vivo," Food and Chemical Toxicology, vol. 52, pp. 97-104, 2013.

[59] E.-J. Yang, S.-K. Ku, W. Lee et al., "Barrier protective effects of rosmarinic acid on HMGB1-induced inflammatory responses in vitro and in vivo," Journal of Cellular Physiology, vol. 228, no. 5, pp. 975-982, 2013.

[60] T. H. Kim, S.-K. Ku, and J.-S. Bae, "Anti-inflammatory activities of isorhamnetin-3-O-galactoside against HMGB1-induced inflammatory responses in both HUVECs and CLP-induced septic mice," Journal of Cellular Biochemistry, vol. 114, no. 2, pp. 336-345, 2013.

[61] T. H. Kim, S. K. Ku, and J. S. Bae, "Persicarin is antiinflammatory mediator against HMGB1-induced inflammatory responses in HUVECs and in CLP-induced sepsis mice," Journal of Cellular Physiology, vol. 228, no. 4, pp. 696-703, 2013.

[62] W.-L. Jiang, Yong-Xu, S.-P. Zhang, H.-B. Zhu, and Jian-Hou, "Forsythoside B protects against experimental sepsis by modulating inflammatory factors," Phytotherapy Research, vol. 26, no. 7, pp. 981-987, 2012.

[63] M. Yang, L. Cao, M. Xie et al., "Chloroquine inhibits HMGB1 inflammatory signaling and protects mice from lethal sepsis," Biochemical Pharmacology, vol. 86, no. 3, pp. 410-418, 2013.

[64] E. S. Seo, B. K. Oh, J. H. Pak et al., "Acteoside improves survival in cecal ligation and puncture-induced septic mice via blocking of high mobility group box 1 release," Molecules and Cells, vol. 35, no. 4, pp. 348-354, 2013.

[65] L. Yang, M. Xie, M. Yang et al., "PKM2 regulates the Warburg effect and promotes HMGB1 release in sepsis," Nature Communications, vol. 5, p. 4436, 2014.

[66] T. Okamoto and T. Kanda, "Glycyrrhizin protects mice from concanavalin A-induced hepatitis without affecting cytokine expression," International Journal of Molecular Medicine, vol. 4, no. 2, pp. 149-152, 1999.

[67] A. Mabuchi, K. Wake, M. Marlini, H. Watanabe, and A. M. Wheatley, "Protection by glycyrrhizin against warm ischemiareperfusioninduced cellular injury and derangement of the microcirculatory blood flow in the rat liver," Microcirculation, vol. 16, no. 4, pp. 364-376, 2009.

[68] M. Ogiku, H. Kono, M. Hara, M. Tsuchiya, and H. Fujii, "Glycyrrhizin prevents liver injury by inhibition of highmobility group box 1 production by kupffer cells after ischemiareperfusion in rats," Journal of Pharmacology and Experimental Therapeutics, vol. 339, no. 1, pp. 93-98, 2011.

[69] N. Kuroda, K. Inoue, T. Ikeda, Y. Hara, K. Wake, and T. Sato, "Apoptotic response through a high mobility box 1 proteindependent mechanism in LPS/GalN-induced mouse liver failure and glycyrrhizin-mediated inhibition," PLOS ONE, vol. 9, no. 4, Article ID e92884, 2014.

[70] X. Wang, R. Sun, H. Wei, and Z. Tian, "High-mobility group box 1 (HMGB1)-toll-like receptor (TLR)4-interleukin (IL)-23IL-17A axis in drug-induced damage-associated lethal hepatitis: interaction of $\gamma \delta$ T cells with macrophages," Hepatology, vol. 57, no. 1, pp. 373-384, 2013.

[71] T. Utsunomiya, M. Kobayashi, R. B. Pollard, and F. Suzuki, "Glycyrrhizin, an active component of licorice roots, reduces morbidity and mortality of mice infected with lethal doses of influenza virus," Antimicrobial Agents and Chemotherapy, vol. 41, no. 3, pp. 551-556, 1997.

[72] M. Menegazzi, R. Di Paola, E. Mazzon et al., "Glycyrrhizin attenuates the development of carrageenan-induced lung injury in mice," Pharmacological Research, vol. 58, no. 1, pp. 22-31, 2008.

[73] M. Ohnishi, H. Katsuki, C. Fukutomi et al., "HMGB1 inhibitor glycyrrhizin attenuates intracerebral hemorrhageinduced injury in rats," Neuropharmacology, vol. 61, no. 5-6, pp. 975-980, 2011.

[74] G. Gong, L. Xiang, L. Yuan et al., "Protective effect of glycyrrhizin, a direct HMGB1 inhibitor, on focal cerebral ischemia/reperfusion-induced inflammation, oxidative stress, and apoptosis in rats," PLoS ONE, vol. 9, no. 3, Article ID e89450, 2014. 
[75] S.-W. Kim, Y. Jin, J.-H. Shin et al., "Glycyrrhizic acid affords robust neuroprotection in the postischemic brain via antiinflammatory effect by inhibiting HMGB1 phosphorylation and secretion," Neurobiology of Disease, vol. 46, no. 1, pp. 147-156, 2012.

[76] L. Luo, Y. Jin, I. D. Kim et al., “Glycyrrhizin suppresses HMGB1 inductions in the hippocampus and subsequent accumulation in serum of a kainic acid-induced seizure mouse model," Cellular and Molecular Neurobiology, vol. 34, no. 7, pp. 987-997, 2014.

[77] T. Yoshida, K. Abe, T. Ikeda et al., "Inhibitory effect of glycyrrhizin on lipopolysaccharide and d-galactosamine-induced mouse liver injury," European Journal of Pharmacology, vol. 576, no. 1-3, pp. 136-142, 2007.

[78] Y. Liu, J. Xiang, M. Liu, S. Wang, R. J. Lee, and H. Ding, "Protective effects of glycyrrhizic acid by rectal treatment on a TNBS-induced rat colitis model," Journal of Pharmacy and Pharmacology, vol. 63, no. 3, pp. 439-446, 2011.

[79] R. Sakamoto, M. Okano, H. Takena, and K. Ohtsuki, "Inhibitory effect of glycyrrhizin on the phosphorylation and DNA-binding abilities of high mobility group proteins 1 and 2 in vitro," Biological and Pharmaceutical Bulletin, vol. 24, no. 8, pp. 906911, 2001.

[80] L. Mollica, F. de Marchis, A. Spitaleri et al., "Glycyrrhizin binds to high-mobility group box 1 protein and inhibits its cytokine activities," Chemistry and Biology, vol. 14, no. 4, pp. 431-441, 2007.

[81] H. Yamaguchi, Y. Kidachi, K. Kamiie et al., "Structural insight into the ligand-receptor interaction between glycyrrhetinic acid (GA) and the high-mobility group protein B1 (HMGB1)-DNA complex," Bioinformation, vol. 8, no. 23, pp. 1147-1153, 2012.

[82] D. Musumeci, G. N. Roviello, and D. Montesarchio, "An overview on HMGB1 inhibitors as potential therapeutic agents in HMGB1-related pathologies," Pharmacology \& Therapeutics, vol. 141, no. 3, pp. 347-357, 2014.

[83] D. J. Shearman and D. Hetzel, "The medical management of peptic ulcer.”, Annual Review of Medicine, vol. 30, pp. 61-79, 1979.

[84] W. Ma, H. Hui, P. Pelegrin, and A. Surprenant, "Pharmacological characterization of pannexin-1 currents expressed in mammalian cells," The Journal of Pharmacology \& Experimental Therapeutics, vol. 328, no. 2, pp. 409-418, 2009.

[85] V. Poornima, M. Madhupriya, S. Kootar, G. Sujatha, A. Kumar, and A. K. Bera, "P2X 7 receptor-pannexin 1 hemichannel association: effect of extracellular calcium on membrane permeabilization," Journal of Molecular Neuroscience, vol. 46, no. 3, pp. 585-594, 2012.

[86] W. Li, J. Li, A. E. Sama, and H. Wang, "Carbenoxolone blocks endotoxin-induced protein kinase R (PKR) activation and high mobility group box 1 (HMGB1) release," Molecular Medicine, vol. 19, no. 1, pp. 203-211, 2013.

[87] V. B. Mehta, J. Hart, and M. D. Wewers, "ATP-stimulated release of interleukin (IL)- $1 \beta$ and IL-18 requires priming by lipopolysaccharide and is independent of caspase-1 cleavage," The Journal of Biological Chemistry, vol. 276, no. 6, pp. 38203826, 2001.

[88] R. J. Griffiths, E. J. Stam, J. T. Downs, and I. G. Otterness, "ATP induces the release of IL-1 from LPS-primed cells in vivo," Journal of Immunology, vol. 154, no. 6, pp. 2821-2828, 1995.
[89] D. G. Perregaux, P. McNiff, R. Laliberte, M. Conklyn, and C. A. Gabel, "ATP acts as an agonist to promote stimulusinduced secretion of IL-1 $\beta$ and IL-18 in human blood," Journal of Immunology, vol. 165, no. 8, pp. 4615-4623, 2000.

[90] A. Surprenant, F. Rassendren, E. Kawashima, R. A. North, and G. Buell, "The cytolytic P2Z receptor for extracellular ATP identified as a P2X receptor (P2X7)," Science, vol. 272, no. 5262, pp. 735-738, 1996.

[91] P. Pelegrin and A. Surprenant, "Pannexin-1 mediates large pore formation and interleukin- $1 \beta$ release by the ATP-gated P2X7 receptor," The EMBO Journal, vol. 25, no. 21, pp. 5071-5082, 2006.

[92] G. Dahl and R. W. Keane, "Pannexin: from discovery to bedside

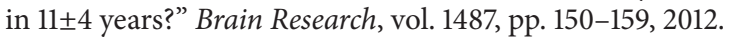

[93] B. Lu, H. Wang, U. Andersson, and K. J. Tracey, "Regulation of HMGB1 release by inflammasomes," Protein \& Cell, vol. 4, no. 3, pp. 163-167, 2013.

[94] R. J. Thompson, N. Zhou, and B. A. MacVicar, "Ischemia opens neuronal gap junction hemichannels," Science, vol. 312, no. 5775, pp. 924-927, 2006.

[95] D. Reigada, W. Lu, M. Zhang, and C. H. Mitchell, "Elevated pressure triggers a physiological release of ATP from the retina: possible role for pannexin hemichannels," Neuroscience, vol. 157, no. 2, pp. 396-404, 2008.

[96] M. Sridharan, S. P. Adderley, E. A. Bowles et al., "Pannexin 1 is the conduit for low oxygen tension-induced ATP release from human erythrocytes," The American Journal of PhysiologyHeart and Circulatory Physiology, vol. 299, no. 4, pp. H1146H1152, 2010.

[97] H. Karatas, S. E. Erdener, Y. Gursoy-Ozdemir et al., "Spreading depression triggers headache by activating neuronal Panxl channels," Science, vol. 339, no. 6123, pp. 1092-1095, 2013.

[98] W. Li, S. Zhu, J. Li et al., "EGCG stimulates autophagy and reduces cytoplasmic HMGB1 levels in endotoxin-stimulated macrophages," Biochemical Pharmacology, vol. 81, no. 9, pp. 1152-1163, 2011.

[99] T. Ishii, T. Mori, T. Tanaka et al., "Covalent modification of proteins by green tea polyphenol (-)-epigallocatechin-3-gallate through autoxidation," Free Radical Biology and Medicine, vol. 45, no. 10, pp. 1384-1394, 2008.

[100] D. E. Ehrnhoefer, J. Bieschke, A. Boeddrich et al., "EGCG redirects amyloidogenic polypeptides into unstructured, offpathway oligomers," Nature Structural and Molecular Biology, vol. 15, no. 6, pp. 558-566, 2008.

[101] J. Zhou, B. L. Farah, R. A. Sinha et al., "Epigallocatechin3-gallate (EGCG), a green tea polyphenol, stimulates hepatic autophagy and lipid clearance," PLOS ONE, vol. 9, no. 1, Article ID e87161, 2014.

[102] C.-P. Li, J. Yao, Z.-F. Tao, X.-M. Li, Q. Jiang, and B. Yan, "Epigallocatechin-gallate (EGCG) regulates autophagy in human retinal pigment epithelial cells: a potential role for reducing UVB light-induced retinal damage," Biochemical \& Biophysical Research Communications, vol. 438, no. 4, pp. 739745, 2013.

[103] H.-S. Kim, V. Montana, H.-J. Jang, V. Parpura, and J.-A. Kim, "Epigallocatechin gallate (EGCG) stimulates autophagy in vascular endothelial cells: a potential role for reducing lipid accumulation," The Journal of Biological Chemistry, vol. 288, no. 31, pp. 22693-22705, 2013.

[104] D. Tang, R. Kang, K. M. Livesey et al., "Endogenous HMGB1 regulates autophagy," The Journal of Cell Biology, vol. 190, no. 5, pp. 881-892, 2010. 
[105] R. Kang, K. M. Livesey, H. J. Zeh, M. T. Lotze, and D. Tang, "HMGB1: a novel Beclin 1-binding protein active in autophagy," Autophagy, vol. 6, no. 8, pp. 1209-1211, 2010.

[106] Y. Zhang, W. Li, S. Zhu et al., "Tanshinone IIA sodium sulfonate facilitates endocytic HMGB1 uptake," Biochemical Pharmacology, vol. 84, no. 11, pp. 1492-1500, 2012.

[107] P. B. Gordon and P. O. Seglen, "Prelysosomal convergence of autophagic and endocytic pathways," Biochemical and Biophysical Research Communications, vol. 151, no. 1, pp. 40-47, 1988.

[108] D. J. Klionsky, "Autophagy: from phenomenology to molecular understanding in less than a decade," Nature Reviews Molecular Cell Biology, vol. 8, no. 11, pp. 931-937, 2007.

[109] T. O. Berg, M. Fengsrud, P. E. Strømhaug, and P. O. Seglen, "Isolation and characterization of rat liver amphisomes: evidence for fusion of autophagosomes with both early and late endosomes," Journal of Biological Chemistry, vol. 273, no. 34, pp. 21883-21892, 1998.

[110] L. Zhao, W. Li, S. Zhu et al., "Green tea catechins quench the fluorescence of bacteria-conjugated Alexa Fluor dyes," Inflammation \& Allergy: Drug Targets, vol. 12, no. 5, pp. 308314, 2013.

[111] J.-G. Wang, S. C. Bondy, L. Zhou et al., "Protective effect of tanshinone IIA against infarct size and increased HMGB1, $\mathrm{NF} \kappa \mathrm{B}, \mathrm{GFAP}$ and apoptosis consequent to transient middle cerebral artery occlusion," Neurochemical Research, vol. 39, no. 2, pp. 295-304, 2014.

[112] A. E. Giakoustidis, D. E. Giakoustidis, S. Iliadis et al., "Attenuation of intestinal ischemia/reperfusion induced liver and lung injury by intraperitoneal administration of (-)Epigallocatechin-3-gallate," Free Radical Research, vol. 40, no. 1, pp. 103-110, 2006.

[113] K. Tamura, B. Alessandri, A. Heimann, and O. Kempski, "The effect of a gap-junction blocker, carbenoxolone, on ischemic brain injury and cortical spreading depression," Neuroscience, vol. 194, pp. 262-271, 2011.

[114] C.-L. Zhai, M.-Q. Zhang, Y. Zhang et al., "Glycyrrhizin protects rat heart against ischemia-reperfusion injury through blockade of HMGB1-dependent phospho-JNK/Bax pathway," Acta Pharmacologica Sinica, vol. 33, no. 12, pp. 1477-1487, 2012.

[115] H. Fang, A. Liu, U. Dahmen, and O. Dirsch, "Dual role of chloroquine in liver ischemia reperfusion injury: reduction of liver damage in early phase, but aggravation in late phase," Cell death \& disease, vol. 4, article e694, 2013.

[116] N. Yun, J.-W. Kang, and S.-M. Lee, "Protective effects of chlorogenic acid against ischemia/reperfusion injury in rat liver: molecular evidence of its antioxidant and anti-inflammatory properties," The Journal of Nutritional Biochemistry, vol. 23, no. 10, pp. 1249-1255, 2012.

[117] W.-L. Jiang, J.-W. Tian, F.-H. Fu, H.-B. Zhu, and J. Hou, "Neuroprotective efficacy and therapeutic window of Forsythoside B: in a rat model of cerebral ischemia and reperfusion injury," European Journal of Pharmacology, vol. 640, no. 1-3, pp. 75-81, 2010.

[118] X. Yin, Y. Yin, F.-L. Cao et al., "Tanshinone IIA attenuates the inflammatory response and apoptosis after traumatic injury of the spinal cord in adult rats," PLoS ONE, vol. 7, no. 6, Article ID e38381, 2012.

[119] H. L. Hellmich, D. R. Rojo, M.-A. Micci et al., "Pathway analysis reveals common pro-survival mechanisms of metyrapone and carbenoxolone after traumatic brain injury," PLoS ONE, vol. 8, no. 1, Article ID e53230, 2013.
[120] Y. Okuma, K. Liu, H. Wake et al., "Glycyrrhizin inhibits traumatic brain injury by reducing HMGB1-RAGE interaction," Neuropharmacology, vol. 85, pp. 18-26, 2014.

[121] W. M. Renno, M. Al-Maghrebi, A. Alshammari, and P. George, “(-)-Epigallocatechin-3-gallate (EGCG) attenuates peripheral nerve degeneration in rat sciatic nerve crush injury," Neurochemistry International, vol. 62, no. 3, pp. 221-231, 2013.

[122] Y. Lim, M. Hedayati, A. A. Merchant et al., "Chloroquine improves survival and hematopoietic recovery after lethal lowdose-rate radiation," International Journal of Radiation Oncology Biology Physics, vol. 84, no. 3, pp. 800-806, 2012.

[123] M. Sánchez-Campillo, J. A. Gabaldon, J. Castillo et al., "Rosmarinic acid, a photo-protective agent against UV and other ionizing radiations," Food and Chemical Toxicology, vol. 47, no. 2, pp. 386-392, 2009.

[124] K. J. Lee, E.-R. Woo, C. Y. Choi et al., "Protective effect of acteoside on carbon tetrachloride-induced hepatotoxicity," Life Sciences, vol. 74, no. 8, pp. 1051-1064, 2004.

[125] D.-W. Kim, H.-I. Cho, K.-M. Kim et al., "Isorhamnetin-3-Ogalactoside protects against $\mathrm{CCl}_{4}$-induced hepatic injury in mice," Biomolecules and Therapeutics, vol. 20, no. 4, pp. 406412, 2012.

[126] X.-D. He, Y. Wang, Q. Wu et al., "Xuebijing protects rats from sepsis challenged with Acinetobacter baumannii by promoting annexin Al expression and inhibiting proinflammatory cytokines secretion," Evidence-Based Complementary and Alternative Medicine, vol. 2013, Article ID 804940, 11 pages, 2013.

[127] Q. Yin and C. Li, “Treatment effects of Xuebijing injection in severe septic patients with disseminated intravascular coagulation," Evidence-Based Complementary and Alternative Medicine, vol. 2014, Article ID 949254, 6 pages, 2014.

[128] Q. Yin and C. Li, “Treatment effects of Xuebijing injection in severe septic patients with disseminated intravascular coagulation," Evidence-Based Complement and Alternative Medicine, vol. 2014, Article ID 949254, 6 pages, 2014.

[129] K. Nakahira, J. A. Haspel, V. A. Rathinam et al., "Autophagy proteins regulate innate immune responses by inhibiting the release of mitochondrial DNA mediated by the NALP3 inflammasome," Nature Immunology, vol. 12, no. 3, pp. 222-230, 2011.

[130] C.-S. Shi, K. Shenderov, N. N. Huang et al., "Activation of autophagy by inflammatory signals limits IL- $1 \beta$ production by targeting ubiquitinated inflammasomes for destruction," Nature Immunology, vol. 13, no. 3, pp. 255-263, 2012. 


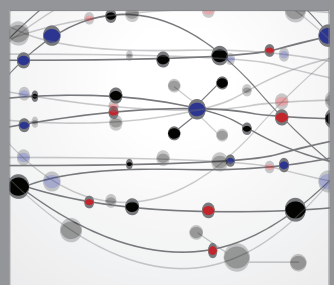

The Scientific World Journal
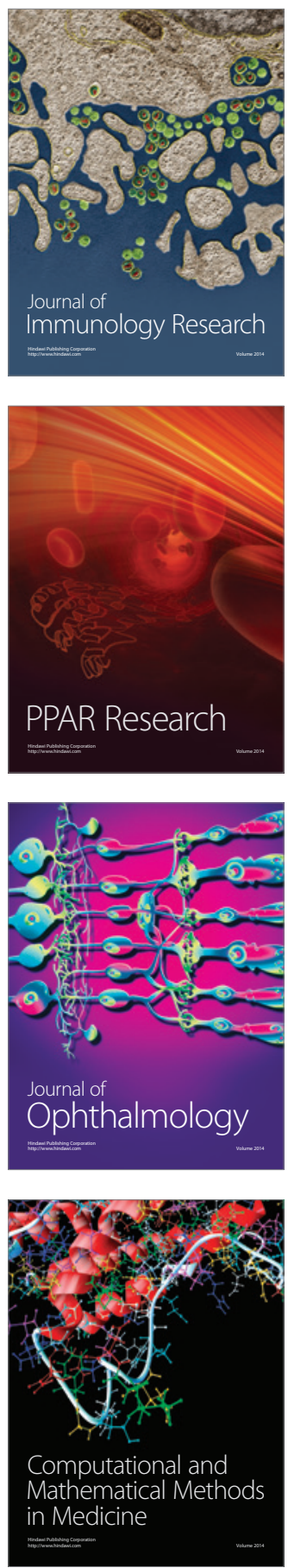

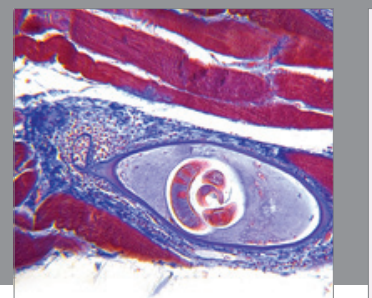

Gastroenterology

Research and Practice
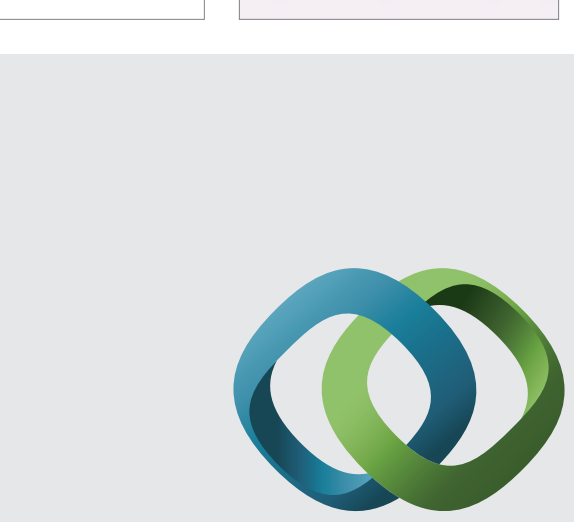

\section{Hindawi}

Submit your manuscripts at

http://www.hindawi.com
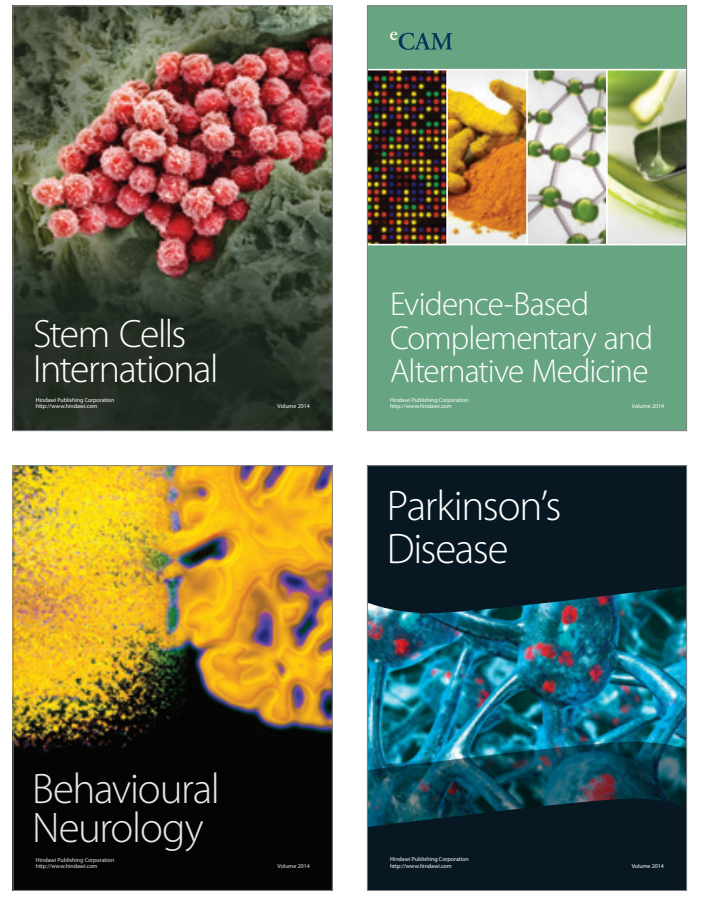
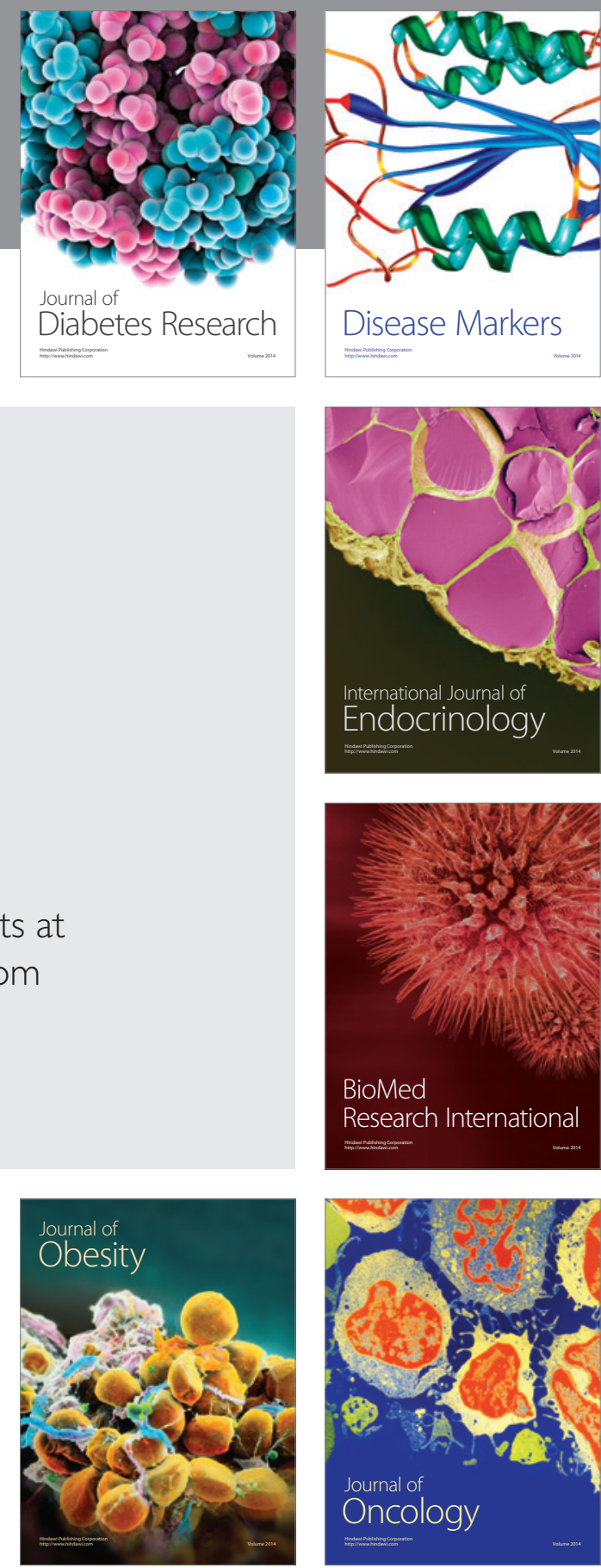

Disease Markers
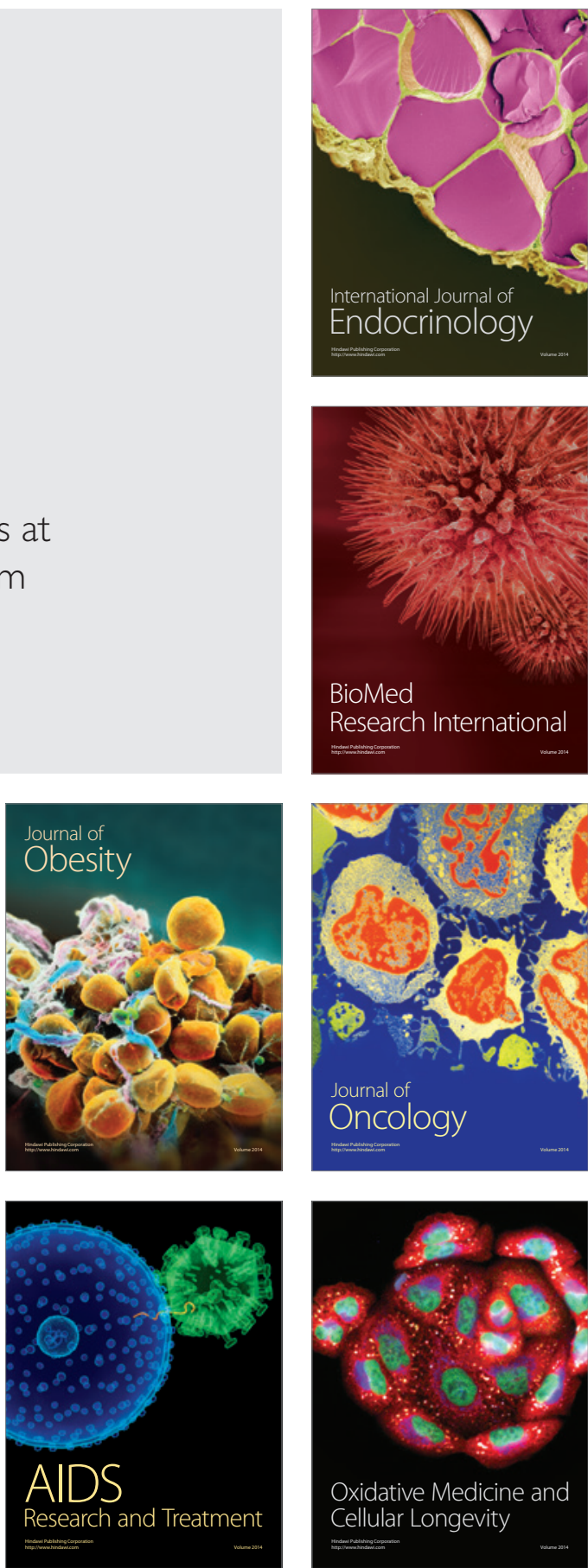